\title{
Variable Production of African American English Across Oracy and Literacy Contexts
}

\author{
Connie A. Thompson \\ Holly K. Craig \\ Julie A. Washington \\ University of Michigan, Ann Arbor
}

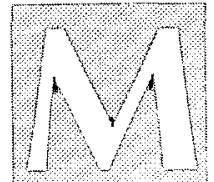

any African American children speak African American English (AAE) at the time of school entry (Craig \& Washington, 2002).

This is particularly true of the large numbers of African American students who reside in major urban centers where $\mathrm{AAE}$ is the predominant linguistic system that is spoken in many communities (Battle, 1993; Dillard, 1972; Washington \& Craig, 1994). AAE is comprised of a selective set of contrastive and noncontrastive morphosyntactic and phonological features when compared to Standard American English (SAE) (Craig, Thompson, Washington, \& Potter, 2003; Green, 2002; Seymour, Bland-Stewart, \& Green, 1998; Washington \& Craig, 1994, 2002). Rates of AAE feature use relate to gender, socioeconomic status (SES), formal schooling experiences, and community influences (Craig \& Washington, 2004; Washington \& Craig, 1994; Washington, Craig, \& Kushmaul, 1998). Children who speak a nonstandard variety of SAE potentially are at a disadvantage when compared to their majority peers because standardized assessment instruments, the curriculum, and instruction are based on SAE vocabulary and linguistic rules.

Nationally, a significant number of African American students demonstrate lower levels of academic achievement compared to their majority peers (Jencks \& Phillips, 1998). This performance discrepancy, which has been called the "Black-White" achievement gap, has been evident for nearly a century (Fishback \& Baskin, 1991). Several factors contribute to the poor academic achievement of African American students. These variables include but are not limited to unequal educational opportunities, low socioeconomic status (LSES) and the associated risk factors (e.g., low caregiver education level), and low teacher expectations. In addition, a large proportion of African American students attend schools in large urban centers, and urban schools often lack resources such as adequate space and materials and adequately trained teachers (Snow, Burns, \& Griffin, 1998). However, performance disparities persist between African American students and their majority peers whether they attend schools in urban centers or in affluent
ABSTRACT: Many African American students produce African American English (AAE) features that are contrastive to Standard American English (SAE). The AAE-speaking child who is able to dialect shift, that is, to speak SAE across literacy contexts, likely will perform better academically than the student who is not able to dialect shift. Method: This investigation examined the AAE productions of 50 typically developing African American third graders across three language contexts-picture description, oral reading of SAE text, and writing.

Results: All participants produced AAE during picture description. A downward shift in contrastive AAE features was evident between spoken discourse and the literacy contexts. More students produced more AAE features during picture description than writing. Both morphosyntactic and phonological features characterized the picture description context. Phonological features predominated during oral reading. In contrast, morphosyntactic features were the most dominant feature in writing.

Clinical Implications: The findings are discussed in terms of dialect-shifting abilities of African American students and the role of writing as a special context to support their entry into dialect shifting.

KEY WORDS: dialect density, African American, elementary grade students, dialect shifting, writing 
suburban school districts. For example, in a study of 15 high-achieving suburban school districts in the United States, Ferguson, Clark, and Stewart (2002) found that compared to their mainstream peers of the same SES, on average, African American students performed lower on standardized achievement tests and achieved lower grade point averages. Moreover, although African American students were represented within the performance distribution, they were underrepresented at the upper end and overrepresented at the lower end of the distribution. Ferguson attributed performance differences to students' home resources such as their access to books and computers and opportunities to engage in rich extracurricular opportunities; to students' background knowledge; and to teacher variables such as degree of encouragement given to students.

Another major factor that likely contributes to the low academic performances of African American students is the influence of $\mathrm{AAE}$ on student learning and performance on standardized tests. Researchers have hypothesized that there is a relationship between AAE and academic achievement (Adler, 1992; Manning \& Baruth, 2000). In particular, failure of African American students to learn SAE grammatical rules has been attributed to delayed development in $\mathrm{SAE}$ reading and writing. Findings from a recent study (Craig \& Washington, 2004) revealed that elementary-grade African American students who were designated as dialect shifters (i.e., low AAE users) outperformed non-dialect shifters (i.e., moderate and high AAE users) on a standardized reading achievement and vocabulary test. This finding suggests that the ability to dialect shift contributes to achievement outcomes in positive ways.

Findings from prior research investigations have shown that during the early elementary grades, students who speak a nonstandard dialect of SAE demonstrate a gradual shift in dialect use to reflect the language of the majority culture (Bountress, 1983; Wolfram, Adger, \& Christian, 1999). This dialectal shift generally is evident by the time children reach 7-8 years of age (Bountress, 1984; Fishman, 1991; Isaacs, 1996). Recently, Craig et al. (2003) also observed a downward shift in AAE feature production during oral reading by second- through fifth-grade African American students. However, it was not a gradual linear relationship. Second graders produced a significantly higher level of dialect than third, fourth, and fifth graders. The third through fifth graders were not significantly different from each other in terms of dialect use, which indicated that the shift actually occurred between second and third grades. This finding of decreased dialect across the elementary grades suggests that students still may be using AAE during the elementary grades, but not at the levels of younger children. Considered together, current literature indicates that African American students enter school speaking AAE but many dramatically decrease use of it in school contexts from third grade on. This literature does not indicate whether the decrease in dialect use occurs uniformly across most classroom tasks or whether the dialect shift is sensitive to context. The study of third graders across language and literacy contexts offers a potentially informative opportunity for examining emerging skills in dialect shifting.
Although it has been determined that several variables may affect AAE production, their influence on the dialect shift process is not clear. Sources of systematic variability in AAE production relate to gender, SES, and community (Dillard, 1972; Ratusnik \& Koenigsknecht, 1976; Washington \& Craig, 1998). Males produce more dialect than females (Dillard, 1972; Labov, 1990; Ratusnik \& Koenigsknecht, 1976; Washington \& Craig, 1998). African American students from LSES homes produce more AAE than their peers from middle-income homes (Dillard, 1972; Ratusnik \& Koenigsknecht, 1976; Washington \& Craig, 1998). Additionally, African American children who reside in segregated, predominately African American communities produce greater amounts and different types of dialect than their peers who live in mainstream or integrated environments (Bountress, 1983; Dillard, 1972).

Discourse context also influences AAE production, and its relationship to dialect shifting is not well understood. Many studies that have examined young children's AAE use have sampled spoken discourse during engagement in spontaneous free play activities and picture description tasks (Craig \& Washington, 2002; Washington \& Craig, 1994, 1998, 2002; Washington et al., 1998). Washington et al. (1998) found differences in children's AAE productions between two language sampling contexts, an unstructured free play task and a semi-structured picture description task. The participants demonstrated production of higher levels of dialect and more varied types in the picture description context than during free play.

Picture description is a semi-structured language sampling context. Like spontaneous language sampling contexts, it avoids imposing adult and SAE models on the child's productions. In addition, it is more ecologically valid in relation to the types of tasks that are completed in the classroom environment. Thus, children's AAE use during picture description likely is more comparable to AAE use in the classroom context. Prior research has focused on preschool and kindergarten students and has not examined AAE use in semi-structured connected discourse with elementary-grade students.

Another important discourse context for classrooms is oral reading. For elementary-grade students, AAE use has been examined in oral reading contexts (Craig et al., 2003; Goodman \& Buck, 1973; Harber, 1982). Harber (1982) found that third, fourth, and fifth graders produced several different $\mathrm{AAE}$ types and tokens during an oral reading assessment. Although there is evidence that AAE is produced during oral reading for elementary-grade students, not all students use AAE in this context (Craig et al., 2003). The absence of contrastive AAE features may be attributed to students' ability to dialect shift. However, dialect shifting cannot be assumed unless the child's production of $\mathrm{AAE}$ in a spontaneous oral elicitation context is known. Similar assumptions might be made relative to the absence of AAE features in written contex.ts. In order to determine whether dialect shifting is occurring and in which contexts it is occurring, AAE productions need to be examined across spontaneous oral production and literacy contexts. The African American child who cornmunicates in $\mathrm{SAE}$, as well as AAE, likely will find him- or herself 
better able to match the language demands of the classroom.

Improving our understanding of AAE productions by elementary-grade students within varied communication contexts, and their development of dialect shifting abilities, seems particularly warranted at this time when there is tremendous national concern about the low academic achievement of many African American students (Grigg, Daane, Jin, \& Campbell, 2003; Jencks \& Phillips, 1998; Snow et al., 1998). The purpose of this investigation was to begin to contribute to this line of research by comparing AAE usage in oracy and literacy contexts for elementarygrade students. The following questions were posed:

- Compared to spoken discourse, are there significant differences in the amount of AAE that is produced during reading and writing?

- What are the characteristics of AAE during spoken discourse, reading, and writing?

- Are there significant differences in the patterns of feature usage characterizing each context?

\section{METHOD}

\section{Participants}

The participants were 50 typically developing African American third-grade males $(n=26)$ and females $(n=24)$. Students resided in the metropolitan Detroit area in either an urban-fringe $(n=23)$ community, where $75 \%$ of the children enrolled in the district were African American, or a midsize central city $(n=27)$, in which African Americans comprised approximately $15 \%$ of the student body in the district (see Table 1). Although it was not a criterion for participation in the present study, all students spoke AAE, as demonstrated by production of at least two AAE features (Washington \& Craig, 1994, 2002) during picture descriptions. School principals identified third graders who were eligible to participate in this investigation. Eligible students were those who had no history of referral to or enrollment

Table 1. The distribution of the participants by gender, community, and low (LSES) or middle (MSES) socioeconomic status.

\begin{tabular}{lccc}
\hline Gender & Central city & Urban fringe & Total \\
\hline Male & & & \\
LSES & 5 & 7 & 12 \\
MSES & 9 & 5 & 14 \\
Total & 14 & 12 & 26 \\
Female & & & \\
LSES & 6 & 4 & 10 \\
MSES & 7 & 7 & 14 \\
Total & 13 & 11 & 24 \\
Total & 27 & 23 & 50 \\
\hline
\end{tabular}

in special education services of any type. Students were admitted to the project on a continuous enrollment basis during the winter and spring terms. Third graders were selected for this project because by third grade, one could expect that students would be reading conventionally. Further, by third grade, most students have well-developed oral language skills and have received repeated exposure to reading and written language conventions.

In the present study, SES and gender were allowed to vary. SES was determined by eligibility or ineligibility to participate in the federally funded free or reduced-price lunch program and/or by the Hollingshead Four Factor Index of Social Status (Hollingshead, 1975). To obtain a Hollingshead index score, participants were assigned point scores based on their primary caregiver's level of education, occupation, marital status, and gender. Index scores were derived from total point scores that corresponded with one of five levels designed to characterize a family's SES. Table 1 presents distribution of the participants by SES and gender.

Only students who demonstrated typical cognitive and language skills were selected to participate in the project. Students were determined to be typically developing based on teachers' and parents' judgments and by performances on the Triangles subtest of the Kaufman Assessment Battery for Children (K-ABC; Kaufman \& Kaufman, 1983) and the Peabody Picture Vocabulary Test-Third Edition (PPVT-III; Dunn \& Dunn, 1997). Triangles, a nonverbal assessment of cognition and mental processing, measures the ability to manipulate small triangles in order to match abstract designs. This subtest is culturally and racially unbiased toward African Americans (Lampley \& Rust, 1986; Willson, Nolan, Reynolds, \& Kamphaus, 1989) and is appropriate for third graders. All students achieved a scaled score (SS) of 7 or greater, which represented performance within one standard deviation $(-3)$ of the mean $(10)$ on this measure. The mean scaled score for the participants in the current investigation was 10.9 , with a standard deviation of 2.2. Typical oral language development was determined by students' performances on the PPVT-III. Participants demonstrated average performances on this task $(M=98.9$, $S D=11.2$ ).

\section{Data Collection and Analysis}

Three randomly ordered linguistic tasks-picture descriptions, an oral reading assessment, and a writing task-were administered to the participants individually. Language samples were collected within each of these contexts by African American and Caucasian examiners trained specifically for these tasks. Examiners included undergraduate and graduate students majoring in psychology, speech-language pathology, and education, as well as certified speech-language clinicians. Whereas the level of education of the examiners varied, it seemed important to determine whether participants' AAE feature use was significantly influenced by examiner differences. The results from one-way analyses of variance (ANOVAs) revealed no significant differences in students' total $\mathrm{AAE}$ productions by examiner in the picture description, $F(2,47)$ 
$=.11, p=.90$; oral reading, $F(1,48)=1.5, p=.22$; or writing context, $F(2,47)=.01, p=.99$. Examiners were assigned to students based on the students' availability on the date of testing.

The three language samples were collected in a single session so that no time lapse occurred between administrations of each task. The combined administration time for the three tasks was approximately $60 \mathrm{~min}$. Whereas dialectshifting was the focus of the current investigation, it seemed important to check the major outcomes of the current project for potential race of examiner effects. Dialect density measures (DDMs) were examined to determine if there were differences in participants' $A A E$ use when the language tasks were administered by an African American versus a Caucasian examiner. Results of independent $t$ tests revealed no systematic differences in students' DDMs by examiner race during picture descriptions, $t(48)$ $=1.6, p=.11$, reading, $t(48)=1.2, p=.22$, or writing, $t(48)=.36, p=.72$.

Language samples were scored for two measures of dialect, a DDM (Craig, Washington, \& Thompson-Porter, 1998) and AAE types using established taxonomies (Craig et al., 2003; Craig \& Washington, 2000; Washington \& Craig, 1994, 2002). Morphosyntactic features were coded using Washington and Craig's definitions (1994, 2002). Phonological features were coded using a recently developed child-based taxonomy (Craig et al., 2003). Craig et al. compiled the phonological features from two sources: adult AAE patterns described in the literature (Stockman, 1996; Wolfram, 1994) and preliminary child-based studies that included regional southern dialect (Hinton \& Pollock, 2000; Oetting \& McDonald, 2001; Rodekohr \& Haynes, 2001). These features were then compared to those produced by elementary-grade African American students during oral reading. Table 2 presents the full set of phonological, morphosyntactic, and combinations of phonological and morphosyntactic features, and these were the scoring taxonomy used in the current investigation.

DDMs were the frequencies of AAE productions (tokens) divided by the total number of words produced in the language sample. Four DDMs per language sampling context were calculated for each student: total AAEDDMs, phonological (PhoDDM), morphosyntactic (MorDDM), and combination (ComDDM). For each system, number of tokens was divided by total words produced in the sample. Each DDM was calculated separately. For example, the PhoDDM was calculated by dividing token frequencies of phonological features by total number of words used in the language sample. The frequency or FREQ command of the Computerized Language Analysis (CLAN) program of the Children's Data Exchange System (CHILDES,

MacWhinney, 1994) automatically generated AAE frequencies of tokens and types.

Picture description. Oral language productions were sampled during an audiotaped picture description task. The picture description context was selected for the following reasons: (a) It is an efficient context to sample spoken English (Washington et al., 1998), and (b) it has high ecological validity to classroom discourse. Each student described three colored action pictures (\#5, \#7, \#24) from the Bracken Concept Development Program (Bracken, 1986) that were presented in random order. Participants were given the prompt to "tell me as much about these pictures as you can." Students were given an additional prompt, "tell me what's happening in the picture," if they just labeled objects and actions that were depicted. The samples were untimed. The mean number of communication units (C-units) produced within each sample was 27.8 , with a standard deviation of 11.3; mean number of words produced per sample was 182 , with a standard deviation of 63 . The mean length of C-units was 6.69 , with a standard deviation of 1.6 .

Following data collection, language samples were transcribed orthographically using the Coding for Human Analysis of Transcripts (CHAT) conventions of CHILDES (MacWhinney, 1994) and segmented into C-units using Loban's (1976) criteria. C-units consisted of independent clauses plus their modifiers, single word responses to adult questions, and children's acknowledgments to prior adult comments.

One AAE combination feature, Zero Auxiliary/Postvocalic Consonant Reduction (AUX/PCR), was not observed in this context likely because it could not be detected. For example, when a student says "I been here a long time," it is not clear whether the underlying sentence structure was: "I have been here a long time, or "I've been here a long time." The former would represent deletion of the auxiljary alone and would be scored as zero modal auxiliary, whereas the latter would represent both deletion of the auxiliary and a postvocalic consonant reduction. Whereas picture description offered no written text to guide these interpretations, the AUX/PCR was not scored. This scoring ambiguity was not a problem in the reading context where the printed targets were available to guide scoring decisions.

Oral reading samples. The Gray Oral Reading TestsThird Edition (GORT-3; Wiederholt \& Bryant, 1992) was administered individually to the students following the standardized administration procedures included in the examiner's manual. This timed oral reading test measures reading rate, accuracy, comprehension, and fluency. Both the child and the examiner wore head microphones and were audio-recorded during test administration using a microphone mixer. A mean number of 349 words $(S D=$ 228 ) was produced by participants during oral reading. The students' oral reading of the passages was scored for AAE tokens and types. Frequencies of AAE tokens produced were calculated manually.

The GORT-3 consists of 13 passages that increase in difficulty based on paragraph and sentence length, grammatical complexity, and vocabulary difficulty. Each passage consists of a single paragraph centered on one topic. The GORT-3 is appropriate for children in the age range of $7 ; 0$ (years;months) to $18 ; 11$. It contains four scores: Rate, Accuracy, Passage (Rate + Accuracy), and Comprehension. The mean (10) and standard deviation (3) for the subtests are the same. Standard scores, percentiles, and ageequivalent scores may be derived from performances on the GORT-3. In addition, an overall reading quotient (ORQ) is calculated from the sums of standard scores of the Passage and Comprehension subtest. The mean ORQ is 100 and the standard deviation is 15 . 
Table 2. Phonological (9), morphosyntactic (24) and combination (8) types of child AAE with examples. (page 1 of 3)

Definition Code Example

\section{Phonological Types}

Postvocalic consonant reduction

Deletions of consonant singles following vowels

"g" dropping

Substitutions of $n /$ for $/ \mathrm{g} /$ in final word positions

Substitutions for $/ \theta /$ and $/ \delta /$

$/ \mathrm{t} /$ and $/ \mathrm{d} / \mathrm{substitute}$ for $/ \theta /$ and $/ \delta /$ in prevocalic positions,

$/ f, t /$ and $/ v /$ substitute for $/ \theta /$ and $/ \delta /$ in intervocalic positions, and in postvocalic positions

Devoicing final consonants

Voiceless consonants substitute for voiced following the vowel

Consonant cluster reduction

Deletion of phonemes from consonant clusters

Consonant cluster movement

Reversal of phonemes within a cluster, with or without consonant reduplication

Syllable deletion

Reduction of an (unstressed) syllable in a multisyllabic word

Syllable addition

Addition of a syllable to a word, usually as a hypercorrection

Monophthongization of diphthongs

Neutralization of diphthong

\section{Morphosyntactic Types}

Ain't

Ain't used as a negative auxiliary in have + not, do + not, are + not, and is + not constructions

Appositive pronoun

Both a pronoun and a noun, or two pronouns, used to signify the same referent

Completive done

Done is used to emphasize a recently completed action

Double marking

Multiple agreement markers for regular nouns and verbs, and hypercorrection of irregulars

Double copula/auxiliary/modal

Two modal auxiliary forms are used in a single clause

Existential it

It is used in place of there to indicate the existence of a referent without adding meaning

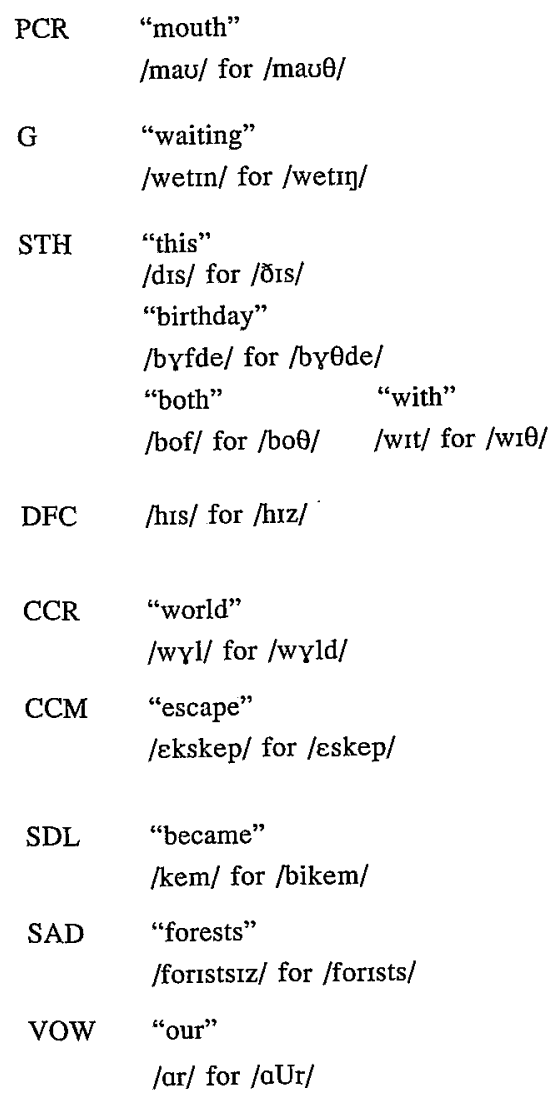

AIN "you ain't know that?"

PRO "and the other people they wasn't"

DON "done set the fire"

DMK "he tries to kills him"

"they are taking the poor hitted boy to a hospital"

MOD "once there was a turtle who chattered so much that she should had no friends"

EIT "I think it's a girl or a boy is yelling" 
Table 2. Phonological (9), morphosyntactic (24) and combination (8) types of child AAE with examples. (page 2 of 3 )

\begin{tabular}{lll}
\hline Definition & Code Example \\
\hline
\end{tabular}

\section{Morphosyntactic Types (continued)}

\section{Fitnalsposetalbouto}

Abbreviated forms coding imminent action

Preterite had

Had appears before simple past verbs

Indefinite article

$A$ is used regardless of the vowel context

Invariant $b e$

Infinitival be coding habitual actions or states

Multiple negation

Two or more negatives used in a clause

Regularized reflexive pronoun

Hisself, theyself, theirselves replace reflexive pronouns

Remote past been

Been coding action in the remote past

Subject-verb agreement

Subjects and verbs differ in marking of number

Undifferentiated pronoun case

Pronoun cases used interchangeably

Zero article

Articles are variably included

Zero copula/auxiliary

Copula and auxiliary forms of the verb to be are variably included

Zero -ing

Present progressive -ing is variably included

Zero modal auxiliary

Will, can, do, and have are variably included as modal auxiliaries

Zero past tense

-ed markers are variably included on regular past verbs and present forms of irregulars are used

Zero plural

$-s$ is variably included to mark number

Zero possessive

Possesion coded by word order so $-s$ is deleted or the case of possessive pronouns is changed

Zero preposition

Prepositions are variably included

Zero to

Infinitival to is variably included
FSB "he fitna be ten"

"he bouta fall"

HAD "he flew with a strong stick in his claws while the turtle had held the stick fast in her mouth"

ART "one day she met a eagle traveling to a far-away lands across the sea"

IBE "and they be cold"

NEG "it not raining no more"

REF "bouta fall and trying to hold hisself back up.

BEN "I been knew how to swim"

SVA "Our cat Mimi like_to sit on the roof"

UPC "her fell"

ZAR "this cake is (the) best present of all"

COP "but she always comes down when it (is) time to eat" "then you'(II) have to wear the brown ones instead"

ING "It was go(ing) to be a good birthday"

AUX "he might _ been in the car"

PST "as soon as she open(ed) her moth, she fall straight into the ocean below"

ZPL "Father went out to buy some pretty flower_"

POS "The boy'()ㅗ grandmother showed him how to put worms on the hook so they would not come off"

ZPR "she sits and looks (at) birds"

ZTO "that man right there getting ready _ slip on his one foot" 
Table 2. Phonological (9), morphosyntactic (24) and combination (8) types of child AAE with examples. (page 3 of 3)

Definition Code Example

Combination Types

Consonant Cluster Reduction + Zero Past Tense

Consonant Cluster Reduction + Zero Plural

Consonant Cluster Reduction + Subject-Verb Agreement

Postvocalic Consonant Reduction + Zero Auxiliary

Postvocalic Consonant Reduction + Zero Past

Postvocalic Consonant Reduction + Zero Plural

Postvocalic Consonant Reduction + Zero Possessive

Postvocalic Consonant Reduction +Subject-Verb Agreement
CCR/PST "mother kiss(ed) them all goodbye"

CCR/ZPL "the children made their bed(ㅇ) and dressed"

CCR/SVA "then she jump(s) on the roof"

PCR/AUX "I'(ve) lost my blue book"

PCR/PST "the boy's grandmother show(ed) him how to put worms on the hook"

PCR/ZPL "I can't find my red shoe(s)"

PCR/POS "the boy'()ㅡㄴ grandmother"

PCR/SVA "Mimi go(es) up the tall tree by the house"

Adapted from "Dialectal Forms During Discourse of Urban, African American Preschoolers Living in Poverty, by J. A. Washington and H. K. Craig, 1994, Journal of Speech and Hearing Research, 37, 816-832. Copyright 1994 by the American Speech-Language-Hearing Association. Reprinted with permission. "Morphosyntactic Forms of African American English Used by Young Children and Their Caregivers." by J. A. Washington and H. K. Craig, 2002, Applied Psycholinguistics, 23, 209-231. Copyright 2002 by Cambridge University Press. Reprinted with permission. "Phonological Features of Child African American English," by H. K. Craig, C. A. Thompson, J. A. Washington, and S. Potter, 2003, Journal of Speech, Language, and Hearing Research, 46, 623-635. Copyright 2003 by the American Speech-Language-Hearing Association. Reprinted with permission.

Written samples. For the writing task, students were instructed to write a story that had a beginning, a middle, and an end. The topic of the story was of their own choosing. If a student demonstrated difficulty identifying a topic, the examiner suggested possible topics, such as a family. event, a pet, or something the child did recently. This task was untimed. The written language samples ranged from 1 to $22 \mathrm{C}$-units, and the mean number of C-units per each sample was $9.7(S D=4.7)$. The mean number of words produced within each sample was $71(S D=36)$. Written language samples were transcribed into CHAT files. The FREQ command from CLAN was used to generate frequencies of AAE types and tokens. The AAE combination feature, AUX/ PCR, again was not scored in this context because like picture description, there was no established target reference in print to guide scoring decisions.

\section{Reliability}

Reliabilities were established for the language samples produced in the picture description, oral reading, and written context and were high across contexts. Three independent observers who had received specialized training in the AAE coding system and who majored in linguistics as undergraduates completed all of the reliabilities. Transcription reliabilities for picture description were established for all of the participants. Approximately $10 \%$ of each language sample was re-transcribed by an independent observer. Reliabilities were calculated by dividing the number of agreements by the number of agreements plus disagreements. Transcription and C-unit reliabilities were high (97\% and $96 \%$, respectively). AAE coding reliabilities also were established for each of the language samples. AAE coding agreements were high for types $(100 \%)$ and tokens $(92 \%)$.
Scoring reliabilities for GORT-3 administrations were also examined. An independent examiner re-scored approximately $10 \%$ of the GORT-3s. Interrater agreement for identifying the presence of a reading variation was $90 \%$, for distinguishing $\mathrm{AAE}$ features from non- $\mathrm{AAE}$ features was $100 \%$, and for identifying AAE types and tokens were both $100 \%$.

Reliabilities were established for the written samples. Point-to-point agreement for C-unit segmentation (93\%) and transcription reliability was high $(99 \%)$. Interrater coding agreement for AAE types and tokens was $100 \%$.

\section{RESULTS}

Multivariate analysis of variance (MANOVA) was applied to the data to examine the influence of SES, gender, and community within contexts. Also within contexts, the three feature systems-phonological, morphosyntactic, and combinations-were examined using pairwise $t$ tests. The alpha level was adjusted to control for the relatedness in these data sets $(.05 / 3=.016)$. Whereas crosscontext comparisons were critical to the design of the study, paired $t$ tests were also used to examine AAE feature production between the linguistic contexts. Results are presented first in terms of major findings within each context, and then in terms of cross-context similarities and differences, as follows.

\section{Within-Context Analyses (Tokens)}

Picture description. All students used AAE during picture description. The total AAEDDMs during picture description varied from .015 to .270 . In other words, some 
students produced one dialectal form every approximately 67 words, whereas others produced one dialectal form every approximately 4 words.

This variability was not related to $\operatorname{SES}, F(7,42)=1.9, p$ $=.18$, or gender $F(7,42)=.20, p=.66$. In contrast, Table 3 shows that the effect of community on total AAEDDMs was statistically significant (cf. means $=.072$ vs. .107 for the central and urban-fringe communities, respectively), $F(7,42)$ $=5.0, p=.03$. However, the variance accounted for correlation effect size was small $\left(\eta^{2}=.11\right)$. This effect size, which represents the percentage of individual variability that can be explained by group membership of the participants, indicated that community predicted only a small amount of the variance of AAEDDMs.

The total AAEDDMs were examined further for relationships among feature systems. Table 4 shows that for picture descriptions, the participants produced C-units with phonological, morphosyntactic, and combined phonological and morphosyntactic features. Phonological features were significantly higher than morphosyntactic features for picture description (cf. means $=.049$ vs. .037 ), paired $t(49)$ $=2.6, p=.011$. The effect size was moderate $(d=.38)$, using a criterion of .30 to .70 (Cohen, 1988). This effect size, which reflects the magnitude of this statistical finding, was considerable. Both PhoDDMs and MorDDMs were greater than ComDDMs within C-units, paired $t(49)=9.3$, $p<.001$, and paired $t(49)=9.3, p<.001$, respectively. The effect sizes, which were identical, were large $(d=1.3)$, using a criterion of .80 or greater. The large effect sizes indicated that the relative importance of these findings was substantial. Considered together, both phonological and morphosyntactic features were produced in the picture description context but phonological features were more frequent, regardless of community.

Oral reading. Most students $(n=46,92 \%)$ produced AAE during oral reading. Four students, $8 \%$ of the participants, did not use AAE within this context. AAEDDMs ranged from .000 to .098 during oral reading. DDMs did not vary systematically by $\operatorname{SES} F(7,42)=.24, p=.62$, or gender $F(7,42)=3.6, p=.07$. Table 3 shows that for community, there was no variation either, $F(7,42)=.01$, $p=.91$.

Table 3. Means and standard deviations for Total African American English dialect density measures in picture description, oral reading, and writing by community.

Context Central city Urban-fringe

\begin{tabular}{lll} 
Picture description & & \\
$\quad$ Mean & $.072^{*}$ & $.107^{*}$ \\
$S D$ & .050 & .060 \\
Oral reading & & \\
$\quad$ Mean & .019 & .021 \\
SD & .020 & .020 \\
Writing & & \\
$\quad$ Mean & .023 & .029 \\
SD & .030 & .050 \\
\hline
\end{tabular}

${ }^{*} p=.03$
Table 4. Means and standard deviations for morphosyntactic, phonological, and combination dialect density measures across picture description, oral reading, and writing contexts.

\begin{tabular}{llll}
\hline Feature & $\begin{array}{c}\text { Picture } \\
\text { description }\end{array}$ & $\begin{array}{c}\text { Oral } \\
\text { reading }\end{array}$ & Writing \\
\hline Morphosyntax & & & \\
$\quad$ Mean & $.037^{1,2}$ & $.003^{1,3}$ & $.013^{2,3}$ \\
$\quad$ SD & .027 & .005 & .012 \\
$\begin{array}{l}\text { Phonology } \\
\quad \text { Mean }\end{array}$ & $.049^{4,5}$ & $.010^{4,6}$ & $.000^{5,6}$ \\
$\quad$ SD & .036 & .011 & .002 \\
Combinations & $.003^{7}$ & $.007^{7}$ & .012 \\
$\quad$ Mean & .004 & .012 & .036 \\
$\quad$ SD & $.088^{8,9}$ & $.020^{8}$ & $.026^{9}$ \\
Total AAEDDM & .058 & .020 & .041 \\
\hline
\end{tabular}

${ }^{1-7} p \leq .015$

Note. The superscripts $\left({ }^{1-7}\right)$ represent significant relationships across contexts. For example, $.037^{1}$ (picture description) and $.003^{1}$ (oral reading) represent the significant differences betwen the morphosyntactic DDMs (MORDDMs) between these two contexts. Similarly, $.037^{2}$ (picture description) and $.013^{2}$ (writing) indicate the significant differences between the MORDDM; between these two contexts. Further, .003 (oral reading) and .013 $3^{3}$ (writing) represent the significant differences between the M[ORDDMs across these two contexts.

Total AAEDDMs again were examined for relationships among feature systems. In the oral reading context, Table 4 shows that phonological, morphosyntactic, and combination features were produced. PhoDDMs were significantly higher than MorDDMs, (cf. .010-.003), paired $t(49)=4.2$, $p<.001$. A large effect size was associated with these differences $(d=.67)$, using a criterion of .80 or greater. Again, a large effect size indicated that the magnitude of this finding was substantial. The phonological feature system was produced at more than twice the level of the morphosyntactic feature system. The ComDDMs were greater than the MorDDMs, paired $t(49)=3.1, p=.004$. The effect size was moderate $(d=.40)$, using a criterion of .30 to .70 . The moderate effect size suggested that the differences between the DDMs were considerable. There were no significant differences between the PhoDDMs and the ComDDMs, paired $t(49)=1.4, p=.16$ (see Table 4). Overall, AAE again was produced during oral reading and phonological features dominated.

Written samples. More than half of the students $(n=31$, $62 \%$ ) produced at least one dialectal feature within their writing samples. Nineteen participants $(38 \%)$ did not demonstrate use of AAE within this context. The total AAEDDMs varied widely from .000 to .234 , which represented production of no AAE features to use of one feature for every four words. The variability of the DDMs in the written samples was not due to the effects of SES $F(7,42)=.16, p=.70$, or gender $F(7,42)=.05, p=.83$. Table 3 shows that for community, there was no variation either, $F(7,42)=.37, p=.55$.

Table 4 shows that phonological, morphosyntactic, and combination features were produced in the writing context. 
Further examination of DDMs in writing showed that morphosyntactic features predominated in the students' writing samples and were significantly greater than PhoDDMs (cf. .013 and .000 ), paired $\mathrm{t}(49)=5.6, p<.001$. The effect size associated with this difference was large $(d=.81)$, using a criterion of .80 or greater. The large effect size indicated that the magnitude of the differences between the MorDDMs and the PhoDDMs was substantial. Phonological features, which were identified by spelling variations [e.g., "told" $\rightarrow \operatorname{tol}(\mathrm{d})]$, were produced at very low levels. The mean ComDDMs (.012) were significantly higher than the PhoDDMs, paired $t(49)=2.4, p=.02$. A moderate effect size was associated with these differences $(d=.33$ ), using a criterion of .30 to .70 . Again, the moderate effect size indicated that the relative importance of this finding was considerable. There were no significant differences between the MorDDMs and the ComDDMs, paired $t(49)=1.3, p=.89$. Considered together, many students continued to produce AAE within the writing samples; however, these features were more likely to be morphosyntactic.

\section{Across-Context Analyses (Tokens)}

In this set of analyses, we compared mean DDMs across picture description, oral reading, and writing contexts. As reported above, all students produced AAE during picture description, 4 students (8\%) did not produce AAE during oral reading, and 19 participants (38\%) produced no $\mathrm{AAE}$ during writing. Only 1 student made a complete shift from AAE to SAE in the reading and writing contexts. All other students produced AAE in either reading, writing, or both contexts.

Total AAEDDMs. Table 4 displays further analysis of the data. We examined the total AAEDDMs, morphosyntactic, phonological, and combination feature systems combined. The mean data are shown in Table 4. Total AAEDDMs varied systematically and significantly between the oral production context during picture description and the two literacy contexts, the oral reading and writing contexts (cf. superscripted table values). The mean AAEDDM in the picture description context was significantly higher than in the reading (cf. means $=.088$ vs. .020 ), paired $t(49)=9.3$, $p<.001$, and writing (cf. means $=.088$ vs. .026 ), paired $t(49)=6.2, p<.001$ contexts. The effect sizes associated with these differences were large (reading, $d=1.3$; writing, $d=.87$ ), using a criterion of .80 or higher. Again, a large effect size indicated that the across-context differences between the AAEDDMs were considerable. No significant differences were evident between the literacy contexts, paired $t(49)=1.1, p=.28$. These findings indicated that the students were demonstrating some emerging level of dialect shifting in the literacy contexts, and these levels were the same for reading and writing.

Morphosyntactic, phonological, and combination DDMs. The picture description context yielded larger MorDDMs $(M=.037)$ and PhoDDMs $(M=.049)$ than reading and writing (see Table 4 ). Similarly, PhoDDMs were higher in oral reading than in writing (cf. $M \mathrm{~s}=.010$ vs. .000). However, the opposite was true during writing, in that MorDDMs were larger during writing than during oral reading (cf. $M \mathrm{~s}=.013$ vs. .003 ). ComDDMs were larger during oral reading than picture description. However, ComDDMs did not differ across the literacy contexts (i.e., oral reading and writing).

\section{Distribution of Specific AAE Types}

Whereas the DDM analyses were token based, it seemed important to examine AAE types in order to have a more complete characterization of cross-context similarities and differences. First, all types of features were examined for their productions in each context. Second, the impact of feature differences was probed by setting a $25 \%$ criterion across participants. In other words, the first analysis examined the number of different features apparent in each context. In the second analysis, the extent to which children produced each feature in each context was examined. These are discussed below.

Picture description. Of the potential set of 41 AAE features possible in this context, 35 were produced. Most of the phonological features ( 7 of 9 ), most of the morphosyntactic features (18 of 24 ), and most of the combination features ( 6 of 8 ) were produced.

Figure 1 displays the use of features across students for those features that were produced at least once by $25 \%$ or more of the participant sample. For picture description, $g$ dropping was the most widely dispersed feature across participants $(84 \%)$. Using the $25 \%$ participant criterion, combinations were not among the features widely used. Morphosyntactic and phonological features were distributed at approximately comparable levels.

Oral reading. For the oral reading context, monophthongization of diphthongs was the most widely dispersed feature across participants (56\%). Morphosyntactic features were not among those produced by $25 \%$ or more of the participant sample. Overall, three phonological features, monophthongization of diphthongs, consonant cluster reduction, and substitutions for $\mid \theta /$ and $/ \partial /$ and two phonological + morphosyntactic combinations, consonant cluster reduction + zero plural and consonant cluster reduction + zero past, were the most widely dispersed (see Figure 1).

Written samples. In the writing context, no single feature was produced by at least $25 \%$ of the participants (see Figure 1).

\section{DISCUSSION}

This investigation compared $\mathrm{AAE}$ usage in reading and writing to spoken discourse by African American third graders. The findings from the current investigation contribute new information about elementary-grade students' emerging ability to dialect shift across oracy and literacy contexts. The major findings are as follows:

- Most third-grade African American students produced appreciable but variable amounts of AAE during spoken discourse. 
Figure 1. African American English phonological, morphosyntactic, and combination feature use across contexts.
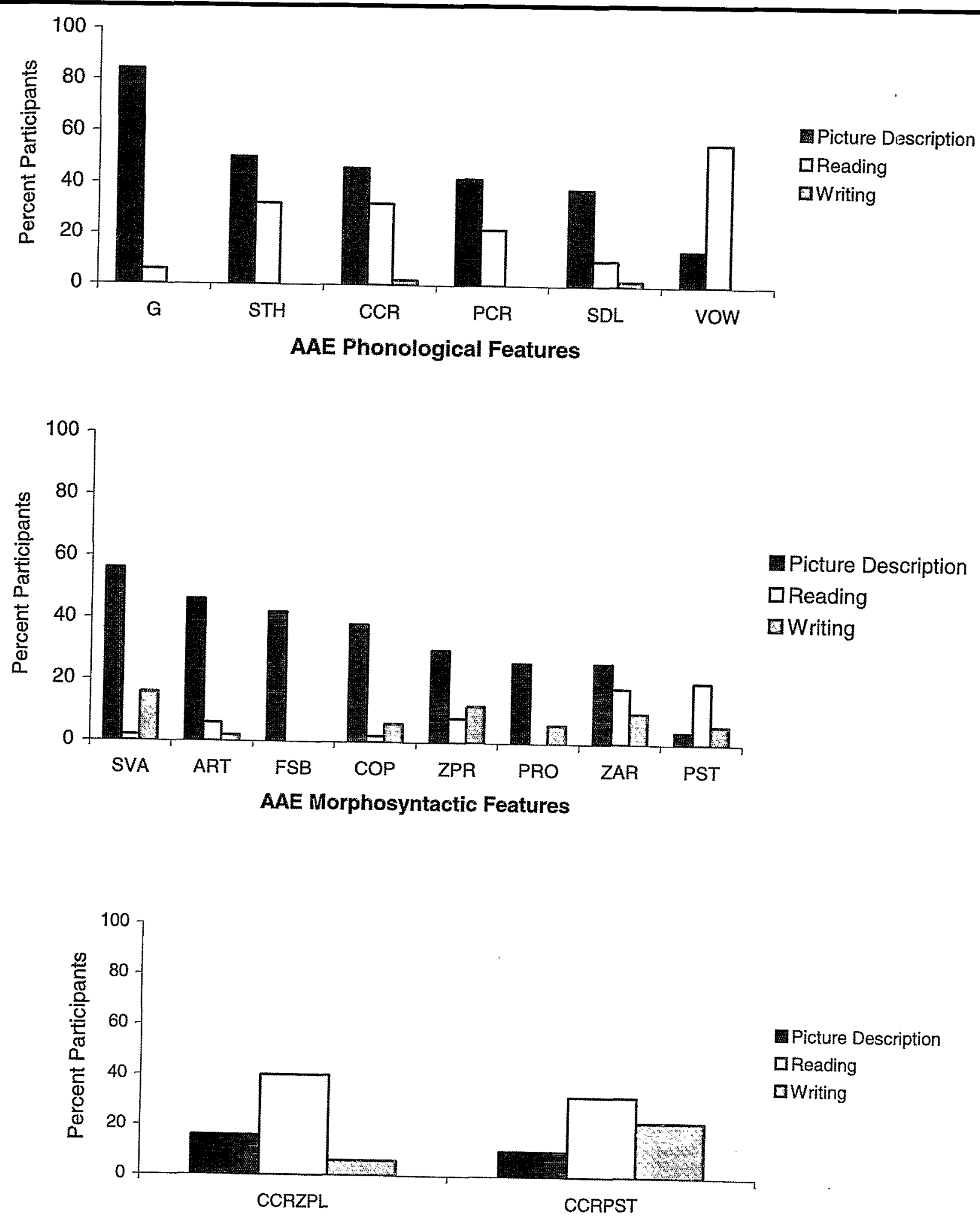

Picture Description 口Reading 口Writing

\section{AAE Combination Features}

Note. $\mathrm{G}=$ "g" dropping, $\mathrm{STH}=$ substitutions for $/ \theta /$ and $/ \mathrm{O} / \mathrm{CCR}=$ consonant cluster reduction, $\mathrm{PCR}=$ postvocalic consonant reduction, $\mathrm{SDL}=$ syllable deletion, VOW $=$ monophthongization of dipthong, SVA $=$ subject-verb agreement, $\mathrm{ART}=$ indefinite article, FSB $=$ fitnal sposetalbouta, $\mathrm{COP}=$ zero copula, $\mathrm{ZPR}=$ zero preposition, $\mathrm{PRO}=$ appositive pronoun, $\mathrm{ZAR}=$ zero article, $\mathrm{PST}=$ zero past tense, CCRZPL $=$ consonant cluster reduction + zero plural, CCRPST $=$ consonant cluster reduction + zero past tense. 
- AAE feature usage decreased from the oracy to the literacy contexts.

- Third-grade African American students demonstrated distinct AAE feature profiles within the oracy and literacy contexts.

Each of these major findings is discussed below.

\section{Appreciable But Highly Variable Amounts of AAE During Spoken Discourse Were Produced}

All participants in the present study were AAE speakers. This is noteworthy because they were not selected to participate based on being a dialect user. Production of $\mathrm{AAE}$ during picture description by the participants in the present study suggests that even though African American children have been exposed to SAE through formal schooling, they have maintained their status as AAE speakers, at least in the early elementary grades. In other words, both contrastive and noncontrastive $\mathrm{AAE}$ features appear to characterize the discourse of typically developing African American third graders. This finding is consistent with other literature, which has observed that many African American students, despite decreasing the amount of $\mathrm{AAE}$ feature use, are still producing $\mathrm{AAE}$ in school contexts (Craig et al., 2003; Harber, 1982). The average level of PhoDDMs and MorDDMs was .088, so that total feature production was one feature for every approximately 11 words. Therefore, total feature production continued to represent an appreciable amount of feature use during picture description. Whereas the average $\mathrm{C}$-unit length in this context was 6.79 , this meant that every sentence produced included at least one contrastive AAE feature.

Like younger children (Craig \& Washington, 2002), the elementary-grade students demonstrated variable production of AAE, as evidenced by the wide range of DDMs produced during picture description. For young African American students, both SES and gender account for some of the variability of AAE feature use in their discourse (Craig \& Washington, 2002; Washington \& Craig, 1998; Washington et al., 1998). The wide range of DDMs produced during picture description in the present study, however, was not attributable to the influences of SES or gender. It is not clear from the findings of the present study why SES or gender no longer exert systematic effects on third-grade AAE feature production. It is the case, however, that the participants in the present investigation had been enrolled in 3 years of formal public education. The effects of schooling on dialect production are not fully understood, but may minimize production differences that relate to SES and gender, as well as decrease dialect production overall.

In the present study, one source of variability, although relatively small, was community. The students who attended schools in the urban-fringe community produced higher levels of dialect than the students who lived in the midsize central city. Community variables were not the focus of this investigation; therefore, unfortunately, explanatory factors are not available from the reported data. It seems important to improving our understanding of the student who is an AAE speaker to discover as many systematic influences as possible that govern dialect production. Accordingly, future research probing community differences and their covariables appears warranted. It is noteworthy that the AAE-speaking students living in the urban-fringe community represented the majority of the student body in their schools. In contrast, students living in the midsize community represented only a small percentage of their student enrollments. It will be interesting in future research to determine whether being an AAE speaker in schools where you speak the dominant or the nondominant language differentially impacts other aspects of language and schooling.

Both morphosyntactic and phonological features characterized the picture description samples. PhoDDMs, however, were produced at significantly higher levels than MorDDMs. The predominance of PhoDDMs during picture description may reflect the underlying nature of AAE in which contrastive phonological features may be more frequent than contrastive morphosyntactic features. As we have suggested elsewhere (Craig et al., 2003), the dominance of the phonological set of AAE features may be due at least in part to differences in opportunity. Morphosyntactic features operate at the level of the morpheme, word, or phrase. Phonological features primarily operate at the smaller, more frequent level of the phoneme. Even though the phonological system consisted of a small number of features, their operation at the level of the phoneme offers a large set of opportunities for their potential occurrence. Although this explanation did not appear sufficient to explain the patterns observed by Craig et al. (2003) for reading, differential opportunities for phonological features to occur cannot be ruled out as an explanation in the picture description context.

\section{AAE Usage Decreased from the Oracy to the Literacy Contexts}

Oral reading. Most of the participants in the present study produced $\mathrm{AAE}$ while reading $\mathrm{SAE}$ text. This finding is consistent with prior investigations of elementary-grade students' use of AAE (Craig et al., 2003; Goodman \& Buck, 1973; Harber, 1982). In other work, Craig et al. (2003) found that DDMs decreased across grades in reading. Craig et al. proposed that the significant decrease in AAE feature production during reading between second and third grade might be associated with students' acquisition of conventional reading skills. In the participating school districts in this investigation, as in most public schools across the nation, the transition from second to third grade includes a shift in reading emphasis from decoding to comprehension (Adams, 1990). By implication, many third graders will have developed competency in phoneme-grapheme correspondences. Skill in associating spoken sounds with written letters may correspond to increasing conformity to $\mathrm{SAE}$, and a resulting decrease in DDM. Future research on the development of the ability to spell may provide a particularly sensitive skill area for improving our understanding of the African American 
student's ability to develop SAE phoneme-grapheme correspondences. A related interpretation for the downward shift in total AAE feature use across oracy and literacy contexts is that it represents children's increased competence in identifying contrastive and noncontrastive AAE features. Whereas at the time of school entry, many African American children speak AAE, this across-context dialect shift may signal the beginning of children's development into becoming competent bidialectal speakers.

Contrastive phonological features predominated during oral reading and, unlike picture description, combinations were produced as well. Phonological features were produced at more than twice the level of morphosyntactic features. The nature of the oral reading context itself possibly influenced the predominance of phonological features during reading. For text, sentence structure relationships may be less susceptible to change than graphemes. In support of this interpretation, none of the phonological features decreased to zero in reading. Two of the three morphosyntactic features that were not used in reading but were frequent in picture description were fitnal sposetalbouta (e.g., he is about to fall $\rightarrow$ he bouta fall.) and appositive pronoun (e.g., it looks like these two boys fell $\rightarrow$ it looks like these two boys, they both fell.). These two features when used would have changed three words to a single lexical form, or added words to the text that were not present. The absence of these features during oral reading further supports the interpretation that the grammatical structure of the reading text is less likely to change than phonological forms during oral reading.

Writing. Like picture description, morphosyntactic, phonological, and combination features were used in writing. However, in contrast to picture description, AAE decreased to one third the level. A plausible explanation for the shift from AAE to SAE in writing, but not during picture description, is that AAE does not have conventional written forms in the same way as SAE. African American students have models for spoken AAE; however, children do not have models for written AAE like they have for spoken AAE. Whereas AAE is an oral linguistic system and not a written system, students likely have minimal opportunities to experience AAE in print. Further, students are exposed to SAE written language conventions upon entering the formal schooling environment and given multiple, varied, and even explicit opportunities to implement these conventions in their writing. Accordingly, limited experience with $\mathrm{AAE}$ written forms and frequent exposure to SAE written language and spelling conventions likely are associated with the shifts from AAE to SAE in writing.

MorDDMs were the dominant system produced in writing, whereas phonological features were the predominant feature system in both other contexts. Why were contrastive phonological features less frequent in writing? One tenable explanation is that literacy instruction for students in the early elementary grades emphasizes decoding (Adams, 1990). Decoding requires the learning of phoneme/grapheme relationships. Therefore, the reduction of phonological features during writing may reflect students' experience with decoding instruction.
Just more than half of the students used AAE in their written language samples and only two features were used by at least $25 \%$ of the students. These findings are particularly noteworthy because nearly all of the participants produced AAE within the other literacy context. The percentage of students who used AAE during oral reading but not during writing was $38 \%$. Whereas current reading theorists propose that reading and writing develop simultaneously (Neuman, Copple, \& Bredekamp, 2000), it is surprising that the students did not use AAE in the same ways within the two literacy contexts. This finding suggests that dialect shifting may be context dependent and that the transfer to SAE may be best supported in writing. Accordingly, writing warrants special attention in future research and curriculum planning because it may represent a window to bidialectalism.

\section{Distinct AAE Feature Profiles Were Evident Within Oracy and Literacy Contexts}

The students presented distinct profiles of AAE feature use within the oracy and literacy contexts. These patterns were apparent when number of different features, as well as dispersion of the features based on the $25 \%$ participant criterion, were examined. In picture description, no combination features were produced. Also in picture description, although phonological features occurred more often, both phonological and morphosyntactic features were frequent. In the oral reading context, phonological and combination features were produced, but morphosyntactic fœatures were infrequent. In the writing context, phonological features were rare, and morphosyntactic and combination features were produced at comparable but low levels (see Figure 1). These profiles underscore how systematic AAE variability is across classroom contexts and the context-dependent nature of feature production during the early elementary grades.

\section{CONCLUSION}

This examination of AAE production by typically developing African American third graders across oracy and literacy contexts revealed systematic differences by classroom language contexts. Every student produced AAE during picture description. On average, they produced one feature for every approximately 11 words.

Amounts of dialect decreased significantly between the oracy and literacy contexts. Students produced AAE in the literacy contexts at approximately one third the level or less than it was used during picture description. On average, students produced one feature for every approximately 44 words in the literacy contexts.

Each context was characterized by a distinctive profile of features. Although phonological features were significantly greater, picture description was characterized by both morphosyntactic and phonological features. Phonological features dominated oral reading. In contrast, morphosyntactic features were the dominant feature system in writing. Writing appeared to support an entry into dialect shifting and the third graders' emerging bidialectal skill. 


\section{ACKNOWLEDGMENTS}

This work was supported by the Center for the Improvement of Early Reading Achievement (CIERA) at the University of MichiganU.S. Department of Education, Office of Educational Research and Improvement, Grant R305R70004, and by the U.S. Department of Education, Office of Educational Research and Improvement, Grant R305T990368. The authors are grateful for the cooperation of the students, teachers, and principals who participated in this study. A special thanks is extended to Carol Connor and Stephanie Potter for their valuable contributions to this manuscript.

\section{REFERENCES}

Adams, M. J. (1990). Beginning to read: Thinking and learning about print. Cambridge, MA: MIT Press.

Adler, S. (1992). Multicultural communication skills in the classroom. Needham Heights, MA: MIT Press.

Battle, D. E. (1993). Communication disorders in multicultural populations. Boston: Andover Medical.

Bountress, N. (1984, November). Teaching standard English to Black English speakers: When to intervene. Unpublished paper presented at the American Speech-Language-Hearing Association Convention, San Francisco.

Bountress, N. G. (1983). Effect of segregated and integrated educational settings upon selected dialectal features. Perceptual and Motor Skills, 57, 71-78.

Bracken, B. A. (1986). Bracken Concept Development Program. San Antonio, TX: The Psychological Corporation.

Cohen, J. (1988). Statistical power analysis of the behavioral sciences (2nd ed.). Hillsdale, NJ: Erlbaum.

Craig, H. K., Thompson, C. A., Washington, J. A., \& Potter, S. (2003). Phonological features of child African American English. Journal of Speech, Language, and Hearing Research, 46, 623-635.

Craig, H. K., \& Washington, J. A. (2000). An assessment battery for identifying language impairments in African American children. Journal of Speech, Language, and Hearing Research, $43,366-379$.

Craig, H. K., \& Washington, J. A. (2002). Oral language expectations for African American preschoolers and kindergartners. American Journal of Speech-Language Pathology, 11, 59-70.

Craig, H. K., \& Washington, J. A. (2004). Grade-related changes in the production of African American English. Journal of Speech, Language, and Hearing Research, 47, 450-463.

Craig, H. K., Washington, J. A., \& Thompson-Porter, C. (1998). Average C-unit lengths in the discourse of African American children from low income, urban homes. Journal of Speech. Language, and Hearing Research, 41, 433-444.

Dillard, J. (1972). Black English. New York: Random House.

Dunn, L., \& Dunn, L. (1997). Peabody Picture Vocabulary Test III. Circle Pines, MN: American Guidance Service.

Ferguson, R. F., Clark, R., \& Stewart, J. (2002). Closing the achievement gap in suburban and urban school communities (Report No. NCREL-13). Naperville, IL: North Central Regional Educational Lab. (ERIC Document Reproduction Service No. ED473122)

Fishback, P. V., \& Baskin, J. H. (1991). Narrowing the BlackWhite gap in child literacy in 1910: The roles of school inputs and family inputs. The Review of Economics and Statistics, 73, 725-728.

Fishman, J. A. (1991). Reversing language shift. Bristol, PA: Multi-lingual Matters.

Goodman, K. S., \& Buck, C. (1973). Dialect barriers to reading comprehension revisited. The Reading Teacher, 27, 6-12.

Green, L. J. (2002). African American English: A linguistic introduction. Cambridge, England: Cambridge University Press.

Grigg, W. S., Daane, M. C., Jin, Y., \& Campbell, J. R. (2003). The nation's report card: Reading 2002 (NCES 2003-521). Washington, DC: U.S. Department of Education, Institute of Education Sciences, National Center for Education Statistics.

Harber, J. R. (1982). Accepting dialect renderings of extant materials on Black-English speaking children's oral reading scores. Education and Treatment of Children, 5, 271-282.

Hinton, L. N., \& Pollock, K. $\dot{\mathrm{E}}$. (2000). Regional variations in the phonological characteristics of African American Vernacular English. World Englishes, 19, 39-58.

Hollingshead, A. B. (1975). Four factor index of social status. New Haven, CT: Yale University, Department of Sociology.

Isaacs, G. J. (1996). Persistence of non-standard dialect in schoolage children. Journal of Speech and Hearing Research, 39, $434-441$

Jencks, C., \& Phillips, M. (1998). The Black-White test score gap. Washington, DC: Brookings Institution Press.

Kaufman, A., \& Kaufman, N. (1983). Kaufman Assessment Battery for Children. Circle Pines, MN: American Guidance Service.

Labov, W. (1990). The interaction of sex and social class in the course of linguistic change. Language Variation and Change, 2 , 205-254.

Lampley, D. A., \& Rust, J. O. (1986). Validation of the Kaufman Assessment Battery for Children with a sample of preschool children. Psychology in the Schools, 23, 131-137.

Loban, W. (1976). Language development: Kindergarten through grade twelve. Urbana, IL: University of Illinois Press.

MacWhinney, B. (1994). The CHILDES project: Tools for analyzing talk (2nd ed.). Hillsdale. NJ: Lawrence Erlbaum Associates.

Manning, M. L., \& Baruth, L. G. (2000). Multicultural education of children and adolescents. Needham Heights, MA: Allyn \& Bacon.

Neuman, S. B., Copple, C., \& Bredekamp, S. (2000). Learning to read and write: Developmentally appropriate practices for young children. Washington, DC: National Association for the Education of Young Children. (ERIC Document Reproduction Service No. ED463904)

Oetting, J. B., \& McDonald, J. L. (2001). Nonmainstream dialect use and specific language impairment. Journal of Speech, Language, and Hearing Research, 44, 207-223.

Ratusnik, D. L., \& Koenigsknecht, R. A. (1976). Influence of age on black preschoolers' nonstandard performance of certain phonological and grammatical forms. Perceptual \& Motor Skills, 42, 199-206.

Rodekohr, R. K., \& Haynes, W. O. (2001). Differentiating dialect for disorder: A comparison of two processing tasks and a standardized language test. Journal of Communication Disorders, $34,255-272$.

Seymour, H. N., Bland-Stewart, L., \& Green, L. J. (1998). Difference versus deficit in child African American English. Language, Speech, and Hearing Services in Schools, 29, 96-108. 
Snow, C. E., Burns, M. S., \& Griffin, P. (1998). Preventing reading difficulties in young children. Washington, DC: National Academy Press.

Stockman, I. J. (1996). Phonological development and disorders in African American children. In A. Kamhi, K. Pollack, \& J. Harris (Eds.), Communication development and disorders in African American children: Research, assessment, and intervention (pp. 117-153). Baltimore: Paul H. Brookes.

Washington, J. A., \& Craig, H. K. (1994). Dialectal forms during discourse of urban, African American preschoolers living in poverty. Journal of Speech and Hearing Research, 37, 816-832.

Washington, J. A., \& Craig, H. K. (1998). Socioeconomic status and gender influences on children's dialectal variations. Journal of Speech, Language, and Hearing Research, 41, 618-626.

Washington, J. A., \& Craig, H. K. (2002). Morphosyntactic forms of African American English used by young children and their caregivers. Applied Psycholinguistics, 23, 209-231.

Washington, J. A., Craig, H. K., \& Kushmaul, A. J. (1998), Variable use of African American English across two language sampling contexts. Journal of Speech, Language, and Hearing Research, 41, 1115-1124.

Wiederholt, J. L., \& Bryant, B. R. (1992). Gray Oral Reading Tests, Third Edition. Austin, TX: Pro-Ed.
Willson, V. L., Nolan, R. F., Reynolds, C. R., \& Kamphaus, R. W. (1989). Race and gender effects on item functioning on the Kaufman Assessment Battery for Children. Journal of School Psychology, 27, 289-296.

Wolfram, W. (1994). The phonology of a sociocultural variety: The case of African American Vernacular English. In J. Bernthal \& N. Bankston (Eds,), Child phonology: Characteristics, assessment and intervention with special populations (pp. 227 244). New York: Thieme.

Wolfram, W., Adger, C., \& Christian, D. (1999). Dialects in schools and communities. Mahwah, NJ: Lawrence Erlbaum Associates.

Received June 16, 2003

Accepted February 11, 2004

DOI: $10.1044 / 0161-1461(2004 / 025)$

Contact author: Connie A. Thompson, Assistant Research Scientist, University Center for the Development of Language and Literacy, University of Michigan, 1111 E. Catherine Street, Ann Arbor, MI 48109-2054. E-mail: connietp@umich.edu 


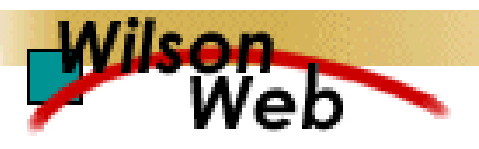

\section{COPYRIGHT INFORMATION}

TITLE: Variable Production of African American English Across Oracy and Literacy Contexts

SOURCE: Lang Speech Hear Serv Sch 35 no3 J1 2004

WN: 0418801952006

(C) The American-Speech-Language-Hearing Association is the publisher of this article and holder of the copyright. Further reproduction of this article in violation of copyright is prohibited without the consent of the publisher. To contact the publisher: http://www.asha.org/

Copyright 1982-2004 The H.W. Wilson Company. All rights reserved. 